\title{
On the Modern Value of Tourism Poetry in Tang Dynasty from the Perspective of Tourism Science
}

\author{
Li-Xia ZHAO \\ School of Literature and Law, Nanyang Institute of Technology, No.80. Changjiang Avenue, \\ Wolong District, 473000, Henan, P.R. China \\ z|z|xz|@163.com
}

Key words: Tourism, Tang Dynasty, Tourism Poetry, Value

\begin{abstract}
This paper attempts to explore the modern value of tourism poetry in the Tang Dynasty from the perspective of tourism, which has far-reaching influence on the Tang Dynasty poetry. In this paper, by means of inductive statistics, comprehensive analysis, classification and other methods, and the use of modern tourism, tourism geography, cultural geography and other related subjects to maximize the excavation of traditional poetry of modern discipline value.
\end{abstract}

\section{Introduction}

Tang poetry, as the peak of Chinese classical poetry, a dazzling monument in Chinese literary history, attracts people's unremitting exploration and research. For the study of Tang poetry, the development has already had the rich historical accumulation, traditional academic forms, such as poetic works, group genres, textual research, artistic features and ideological culture, are still being excavated in depth, and the new theories and methods of the research of Tang poetry are emerging, and the most prominent embodiment is the macroscopic and pluralistic view of the research field, and interdisciplinary research on horizontal integration.

\section{Definition: Ancient Tourism Literature and Modern Tourism Literature}

Tourism science and its extension tourism literature belong to the modern subject, however, "tourism" and "tourism literature" ancient, if the characteristics of modern tourism literature in the concept of the modern tourism life, ignoring the ancient long and long tourism practice, will be divided the development of tourism Literature of the historical ductility, but also cut off the tourism activities from the ancient to the continuity of the venation, a large number of literary works reflecting ancient tourism activities will not be covered, so the extension of the concept of tourism literature should also consider the characteristics of ancient tourism literature. As Zhang Xiangzheng said: "Tourism" in the definition of tourism literature, advocated the use of history, the development of the vision to understand, ancient poetry norms, Jinwen this standard, the ancient works of leniency, modern works strictly, not to the ancient law, to insist on unity; For ancient tourism literature, some scholars thought, "' Tourism literature ' is both ancient and young literature, Young is because as a discipline, it is booming of the emerging disciplines, ancient is because in China's long history of literature, there is always a bright trail of tourism literature, a large number of mountains of water in the past has become a masterpiece, so that Liu Yan Autumn said: ' Half of Chinese literature is tourism literature '. The long ancient tourism literature helps to explain with the theory of modern discipline, and will also radiate new boundless vitality. The ancient tourism literature works of "tourism" is not much, but does not affect the nature of the works of tourism literature, ancient tourism literature on the "Tour View", "Tour", "Travel", "winning" and other words expressed.

"Shan" is a book which is closely related to travel, but it is not a true tourist work. "The Book of Songs", "Chu Ci" also has about natural landscapes or travel notes content, such as "Ye Wind and spring": "I think fat spring, the forever sigh." Think and dive, my heart leisurely. Travel to write my

${ }^{1}$ B. Mckercher et al.Rating tourism and hospitality journals [J].Tourism Management, 2005, (6): 1-18. 
worries. "And so on is the way to describe the natural beauty." and $\mathrm{Qu}$ Yuan in the "Chu Ci" is the landscape scenery and the subjective feelings of personal integration, to achieve more profound artistic conception, such as "Nine song, Mrs. Xiang": "Emperor son down to the north, the eyes Boletus boletus XI." "Then the combination of love and scenery organic integration." These literary works record the beginning of ancient tourism, but these works do not conform strictly to the strict significance of tourism literature standards, can only be categorized as the gestation period of tourism literature works.

To the Han Dynasty Sima Qian for the "Shiji" and travel around the world, for the collection of first-hand historical data and visit, can be described as "weeks around the mountains", just completed from the unconscious travel to conscious consciousness of the transition. With the consciousness of tourism activities, the literati will take the form of poetry, text, and so on; the real tourism literature is also produced. The Fengshan of Madibur in Eastern Han Dynasty was considered as the earliest travel literature, recorded the Madibur with Guangwu Xiu Fengshan Taishan, the text of the description of what I saw along the way, and the tall and steep mountain to the detailed depiction, although this text cannot be said to be a typical travel, but already has the basic characteristics of travel. After the Fengshan instrument, the works of landscape literature began to appear in the Han and Wei dynasties. Along with it, the term "tourism" also appears frequently in literary works, such as the first appearance in Shen's "Sad Line": "Tourism Mei Spring, Spring Mei visitors." "The Old Tang book · Zhao Yin Biography" has: "tourism Jiang to avoid misfortune." Although not all of the tourism in the article refers to tourism, but it has some similarities with the tourism of modern literature.

According to the retrieval of the electronic Literature of Tang poetry, "The Whole Tang poetry" in the "tourism" as the title of the poem has five, that is, Wang Jian's "Early winter tourism fan Cool Public", Jia's "tourism", Liu Yan "spring Tourism", Li Changfu "Tourism injury Spring". The term "tourism" appears in verse 25 times, such as Bai Juyi's "Jianghai Drift of tourism, a bottle of Back" ("sent to Tonglu Hall with Tricundo after the drunken"), Zhang's "Over the ridge million, tourism through this dilute" ("Ridge Table every Past") and so on. Although only from the "tourism" for the title or into the number of poems to look at, does not seem to highlight the advantages in the category of poetry, but the existence of a large number of tourism activities in the early Tang Dynasty and related poetry creation is an indisputable fact, moreover, "the whole Tang poetry" in the "tour" as the title of the poem is also a minority. In a word, throughout the history of ancient Chinese literature, the waves of tourism literature have always been merged, and in some times it has become a wave of billows that kiwi the landscape.

From the above to the history of tourism literature rough carding, it is not difficult to find in ancient tourism literature text, although the works waves colorful, magnificent, but whether it is the landscape tourism poetry or travel prose, "tourism" expressed not much, and instead of "Travel", "tour" and other words. This is because "tourism" as the concept of the word after all originated from the West, on the other hand, it is proved that the "tourism" overview is not enough to outline the full picture of ancient tourism literature.

In view of the numerous appellation of ancient tourism literature, there are many kinds of cross categories related to tourism, referring to the connotation of ancient and modern "tourism", the broad sense of tourism literature is not only a tourism for the purpose of poetry, such as the ancient part of the Exile poetry, Frontier poetry, pastoral poetry, poetry content has a large description of the activities of scenic spots. This kind of work is not only large in quantity, but also closely related to tourism, so it should be classified as the category of tourism literature in actual research operation. In short, whether it is ancient tourism literature or modern tourism literature, the criteria of judgment are in the works to reflect the tourists in the process of watching the activities, and to obtain some kind of emotional or aesthetic experience. Or there should be three basic elements: the subject of tourism has a clearer sense of "sightseeing" or "investigation and research", or the consciousness of tourism when it comes to the water and the tourist object must have the value of traveling, whether it is natural scenery or folk customs and derive an emotional or aesthetic experience from it. 


\section{Value: the Modern Value of Tourism Poetry in Tang Dynasty}

The modern academic tentacles have been extended to the field of historiography, art, philosophy, religion, aesthetics and even architecture, regional traffic, and the exploration of the traditional poetry with the interdisciplinary thinking helps to open up the new field of the Tang poetry field which has not yet been covered. At the same time, it brings the Tang poetry into the field of modern science and further realizes the modern value of classical poetry. Choose to take the Tang Dynasty person's traveling activity and the traveling poetry creation as the cut-in point, based on the relevant theories of modern tourism and the tourism practice in the Tang Dynasty, this paper defines, combs and sums up a series of problems related to tourism poetry in the early Tang Dynasty, and on the basis of summarizing the related essence of Tang tourism poetry, Realize the benign docking of classical poetics and modern tourism.

As to the necessity of research, tourism, as a practical activity of human being, is always in the history of human society, and in the synchronized Chinese literature works of the past dynasties, the Li-Cai of the tour, the tour, the tour, is also the pitch. Although the ancient classics did not list "tourism" category, but it cannot be denied that in the long history of Chinese literature, a large number of sightseeing works conform to the definition of modern tourism literature, or there is some similarity. Especially in the early Tang Dynasty, China's ancient tourism entered a period of rapid development, at the same time, the poetry itself developed into the Tang Dynasty has been formed and Hing and the metrical pattern of large lines of poetic state, into the poetic creation of freedom and the degree, the state of the mature period of norms, The tourism poetry works, which are intertwined by the hatchback collision, naturally become an indispensable part of Tang poetry.

The value of tourism poetry in the history of poetry in Tang Dynasty, the reason why the tourism poetry is divided from the whole of the Tang Dynasty poetry, is not only the special and independent way of life which appeared in the Real Society of the Tang Dynasty, but also the unique features that the tourism poetry has not possessed in other social themes. The most profound influence of literati's rich and pluralistic tourism activities in Tang Dynasty was its artistic innovation and spiritual aim. The tourism of the Tang Dynasty greatly expands the vision and scope of the poetry creation, enriches the content and subject matter of the Tang poetry creation. For the poets, the novelty and strangeness of tourism bring great satisfaction to the new and different psychological demands. A large number of people from the poet's travels, enrich the vision of the poets, impact the senses of poets, and expand the imagination of poets. When poets wander across the vast expanse of space for various reasons, whether it is profound meaning of the cultural landscape, or the vast expanse or the natural landscape of the cold, all the poets to carry out boundless imagination and association, poetry people Quiet thinking is activated, the poem once endowed with imagination, will produce countless new, untouched fresh work. The poetry people see the eye, the ear of the smell, the heart of the feeling all appealed to the pen, together into the ancient poetic language of the earthquake. From all Tang poems, it can be seen that the contribution of tourism poetry in the Tang poetry, "The Whole Tang poetry" in the tourism poems not only a considerable number (preliminary selection, only Pengting to the version of "Full Tang poetry" about tourism poetry there are 3,000 than) and outstanding artistic achievements, many poets have come from the famous poems from their travels.

At the same time, the tourism activities of the poets also promoted the Liang of the early Tang poetry to get rid of the wind of the rhythm and the reform of the ultimate strength. The development of poetry to the Tang Dynasty, poem and style have achieved relatively self-conscious. In the form of pluralistic Tang poetry, both have been unprecedented development, the perfection of poetic style and character of Tang poetry, besides the function of the development law of poetry itself, should be attributed to the emotional overflowing of poets and the bursting of poetry, the single poetic form has not enough to satisfy the poetic expression of the poets, so it has contributed to the development and maturity of various poetic forms. Try to Bo in the "Yue State Autumn feast

2 Craik, J. The culture of Tourism [a]. Rojek, C\& Urry, J. Touring Cultures: Transformtions of Travel and Theory [c]. London: Routledge, 1997: 113. 
shanting Preface," said: "is to Dongshan Hope, Lin thank of the text, more than the Southland, Jiangshan to help Cupping gas." "It is pointed out that Xie Lingyun and Qu Yuan are both poetic creations of the natural landscape of the land they visit, and the poet's talent in Tang Dynasty is not so." The value of tourism literature creation has been widely affirmed, as Mao Zedong said: "The benefits of a great trip!" The peak of the summit, a list of small mountains, the sea of the pan-yellow, the start of the instantaneous river lost. Ma Qian overlooking Xiaoxiang, Pan-West Lake, calendar Kunlun, Zhou Mountains, and its mind is wide."

In terms of the value of the Tang Dynasty tourism poetry in the whole history of tourism poetry, the ancient tourism poetry and even the whole tourism literature are consistent continuous development process. Tourism literature has a long history and is still in the ascendant. The development of ancient tourism literature has contributed to the level of tourism and literary history of the times, generally divided into the foundation period (pre-Qin and Han dynasties), the formation of the period (Wei, Jin, Six dynasties), prosperous period (Tang and song), prosperity and derivation period (Yuan Ming and Qing Dynasty), can be seen in the Tang period of tourism from the formation to prosperity of the key time.

Before the Tang Dynasty, the record of tourism activities was more than 0 broken, even if only a small scale is occasionally. To the Wei, Jin, northern and Southern Dynasties period, in the social background of division and turbulence, political chaos, wen people even to the landscape, the majority is to escape the reality, Lin Quan, send the soul in rivers, through the Lingshan Xiu water purification soul, so into the scale of tourism activities, more out of the present In the Tang Dynasty, tourism activities and related literary works developed to a peak stage, which benefited from the prosperity and stability of the early Tang Dynasty to the prosperous society, providing a stable environment factor and material guarantee for the travel from the emperor to people, and also created the leisure interest of the whole nation. On the other hand, it is also the first prosperous Tang Dynasty literati self-confidence heroic breadth of mind and full of abundant emotional ambition to create the early Tang Dynasty tourism Poetry rapid and rapid development. Therefore, the Tang Dynasty tourism poetry not only in the continuation of the development of Wei and Jin poetry and prosperity of the key period, and in this period of tourism poetry created by the brilliant achievements of future generations cannot be reached.

\section{Reference: Exploring the value of tourism poetry in Tang Dynasty from the perspective of tourism science}

As far as the cognition and dissemination value of tourism poetry is concerned, the poem is based on the poetry and the scenery. The relationship between landscape and poet is a kind of mutual treatment and mutual use, and the Qing people deqian the relationship between landscape and poet: "Jiangshan and poets are treated as well." Jiangshan is not the poet, then rocky rock Yuan, the world longitudinal with spectacular, eventually Monengzhao in the eyes of the ancients in the world. The poet is not the most jiangshan, then although there is the heart of the scenery, Rex Pen, and solitude alone, silence no news, what by inspiring the heart, a spit its Hao Han qi? But two-phase to meet, the heart of the strange universe of the strange and the singular of the diction can be circulated in Jamer. "Rich and varied mountains and rivers, relics, customs, anecdotes are inspiring the poet's creative passion, prompting its" to be a poem chant ", the past return. And all kinds of landscape resources also depend on tourism poetry Zhang name, yellow Crane Tower, Stork House, Lushan, Dongting Lake, West Lake and many other well-known scenic spots, in addition to its own beauty of the characteristics of the beautiful, but also by the reputation of the sound of the Cuihao, "Yellow Crane Tower", Li Bai's "Wang Lushan Waterfall Water", Zhihuan's "Deng Que Lou", Meng Haoran's "to the Dongting Lake to give Zhang Prime Minister," and so on, it is the poetry of the color of the word to enlighten scenic spots, scenic spots and deepen the special effects of attractions, a few words, that is, the aesthetic characteristics of scenery, memorable, poetry and attractions together to become a timeless masterpiece. The remarkable dissemination value of tourism poetry has already been affirmed by the ancients, such as the Qing people Xie in the original poem, under the outer part of the poet to explore the natural landscape of mountains and rivers to highlight the 
role: "The Life of Heaven and earth is a landscape also, its Youyuan strange risk, heaven and earth cannot be cut its wonderful, own person's eyes and ears, and the wonderful beginning of the landscape. The value of the cognition and dissemination of tourism poetry lies in the prominence of poetry to the people's tourism activities in the early Tang Dynasty, it is by the poet on behalf of the tourism status of the description, only to enable modern people can be more objective reduction at that time all the tourism Grand Tour, and both to the early Tang Dynasty tourism fashion, scholars psychology, social customs and other times the overall grasp of the style.

As far as the value of tourism poetry to modern tourism is concerned, it has been mentioned that tourism literature, including poetry, plays an important role in beautifying and publicizing scenic spots. Nature's God show lends the pen of the people to the world. Even many landscapes are not originally famous, all because the poet's chant to famous. such as Li Bai "sitting alone jingting" of the Jingting, Zhang after the "Maple Bridge Night Parking" of Hanshan Temple, Bo "Pavilion" to pavilion, similar examples abound. Tourism this has a certain cultural significance, so many modern attractions because of the poet's compose and more cultural characteristics, attracting visitors because of poetry and visit the scene. "Maple Bridge Night Parking" in Japan widely circulated, the Japanese travel to Suzhou, more to see Zhang poetry carved. Rhyme bells thousand spread, Cold Mountain Temple therefore famous. At the same time, the tourism poetry also has the function of promoting the tourist culture esthetic accomplishment. The excellent travel poetry is like the Wisdom tour guide, guides the reader to choose the best viewpoint, the angle of view, the vision, and unfolds the artistic imagination and the sentiment dint, comprehensively appreciates the scenic spot the atmosphere the beauty, the beautiful scenery and the charm beauty. The development of tourism poetry has become an important tourist resource in China, and the Chinese tourism industry is becoming one of the major tourism countries in the world, which has inestimable important value for the large number of literary works left by literati in the past dynasties, which helps tourists to improve their appreciation level, imagination level and aesthetic level.

\section{Conclusions}

The value of tourism poetry in the Tang Dynasty is far-reaching, but there is no systematic research on the tourism poetry in the Tang Dynasty. there are still insufficient attention and insufficient attention, which has not paid much attention to the modern value of the Tang Dynasty tourism poetry, especially the modern significance of the Tang tourism poetry. This also leaves a great space for the study of such poetry, and the study of classical tourism poetry from the perspective of modern tourism science will also build up the benign docking of traditional poetry and modern subjects.

\section{References}

[1] B. Mckercher et al.Rating tourism and hospitality journals [J].Tourism Management, 2005, (6): $1-18$.

[2] Craik, J. The culture of Tourism [a]. Rojek, C\& Urry, J. Touring Cultures: Transformtions of Travel and Theory [c]. London: Routledge, 1997: 113.

[3] Munday,J.Introducing Translation Studies.London:Rout-ledge,2001,115-117

[4] Shen Zuxiang. Culturology of Tourism.Fuzhou: FujianPeople's Publishing House, 2011.

[5]Robinson,D.Translation and Empire:Postcolonial Theories Explained.Manchester:St Jerome,1997,116

[6] Venuti,L.The Translator's Invisibility.London and NewYork: Routledge,1995,20

[7]Richards,I.A. Towards a Theory of Translating in A.F. Wright. Studies in Chinese Thought.Chicago:University of Chicago Press, 1953,250 